\title{
Running-in friction of hip joint replacements can be significantly reduced: The effect of surface-textured acetabular cup
}

\author{
David NEČAS ${ }^{1,}$, Hatsuhiko USAMI ${ }^{2}$, Tatsuya NIIMI ${ }^{3}$, Yoshinori SAWAE ${ }^{4}$, Ivan KŘUPKA ${ }^{1}$, Martin HARTL $^{1}$ \\ ${ }^{1}$ Faculty of Mechanical Engineering, Brno University of Technology, Brno 61669, Czech Republic \\ ${ }^{2}$ Faculty of Science and Technology, Meijo University, Nagoya 468-8502, Japan \\ ${ }^{3}$ Kanefusa Corporation, Nagoya 480-0192, Japan \\ ${ }^{4}$ Faculty of Engineering, Kyushu University, Fukuoka 819-0395, Japan \\ Received: 13 August 2019 / Revised: 17 October 2019 / Accepted: 05 December 2019 \\ (C) The author(s) 2019.
}

\begin{abstract}
Hip joint replacements represent the most effective way of treatment for patients suffering from joint diseases. Despite the rapid improvement of implant materials over the last few decades, limited longevity associated with wear-related complications persists as the main drawback. Therefore, improved tribological performance is required in order to extend the service life of replacements. The effect of surface texturing of ultrahigh molecular weight polyethylene (UHMWPE) acetabular cup was investigated in the present study. Unique tilling method was utilized for manufacturing the dimples with controlled diameter and depths on the contact surface of the cup. The experiments with four commercial femoral components and two model lubricants were realized. The main attention was paid to a coefficient of friction considering the differences between the original and the dimpled cups. Results showed remarkable lowering of friction, in general. Focusing on the simulated human synovial fluid, friction was reduced by $40 \%$ (alumina ceramic), $38.8 \%$ (zirconia toughened ceramic), $25.5 \%$ (metal), and $9.9 \%$ (oxinium). In addition, the dimples helped to keep the friction stable without fluctuations. To conclude, the paper brings a new insight into frictional behaviour of the hip replacements during running-in phase which is essential for overall implant lifespan. It is believed that proper surface texturing may rapidly improve the life quality of millions of patients and may lead to considerable financial savings.
\end{abstract}

Keywords: hip joint replacement; friction; texturing; dimple; longevity

\section{Introduction}

It is often reported in literature that human joint replacements suffer from limited longevity which is usually associated with aseptic loosening due to osteolysis [1, 2]. Osteolysis is a wear-related problem indicating the importance of tribological performance of the implants [3,4]. Therefore, correlation between lubrication, friction, and wear has to be well understood when aiming on the improved durability of the replacements. Regarding wear, it was shown that wear rate is significantly higher during running-in phase $[5,6]$.
It is assumed that wear is a consequence of elevated friction associated within sufficient lubrication. Recently, number of papers dealt with lubrication analysis using optical methods [7, 8]. Various effects such as kinematic conditions [9], material and geometry [10], or the role of synovial fluid (SF) constituents [11, 12] were clarified. However, in an effort to lengthen the implant lifespan, fundamental analyses have to be supported by suggestions. The aim is to enhance lubrication performance, thus decreasing friction during running-in to slow down the wear process. From the engineering point of view, surface texturing

* Corresponding author: David NEČAS, E-mail: David.Necas@vut.cz 
seems to be very effective solution [13-15].

Considering the application of surface textures on artificial joints, most of the previous studies were focused on wear rate evaluation. Pilot study was provided by Ito et al. [16]. The authors applied concave dimples on the surface of metal femoral head, finding significant reduction of counter polyethylene (PE) surface wear. The positive effect was attributed to reduction of abrasive wear by reservoirs for released particles and improved lubricity due to continuous supply of the lubricant stored in the dimples. The same material combination was later tested in pin-onplate configuration while the results confirmed reduction of wear rate. It was pronounced that suitable shape of the textures may extend longevity of implants by more than two times compared to smooth sliding surfaces [17]. The study was extended by Borjali et al. [18], who examined effect of the dimple pattern made on metal polished surface sliding against PE specimen. Three PE based materials used for prosthetic joints were investigated; UHMWPE, highly crosslinked PE (HXPE), and vitamin E highly cross-linked PE (VEXPE), respectively. In general, the lowest wear rate was observed for VEXPE. Nevertheless, the effect of surface texturing was the most apparent in the case of conventional UHMWPE. Recent paper introduced by Langhorn et al. [19] confirmed previous findings about metal-PE contact pair. The authors observed reduction of wear rate by more than $50 \%$ when textured metal surface was employed.

Frictional behaviour of metal-PE contact was studied by Cho and Choi [20]. Pin-on-disc sliding tests were conducted while the contact surface of the disc was modified. Various depths and surface coverage densities were investigated. Lowering of friction was observed regardless the texturing parameters. For the given conditions, $25 \%$ surface coverage with the dimples having the depth $25 \mu \mathrm{m}$ were found to be optimal. The effect of micro texturing on friction and wear of ceramic materials was discussed by Roy et al. [21]. Pin-on-disc tests were performed under loading conditions corresponding to normal gait of a hip joint. Both friction and wear were reduced significantly, specifically by $22 \%$ and $53 \%$. It is apparent that pin-ondisc does not correspond to the real joint arrangement. Since it was shown that contact conformity plays an important role, Choudhury et al. [22] focused on the effect of the dimples made on the femoral heads on a friction coefficient. The measurements were realized using pendulum hip simulator in order to ensure real contact geometry [23]. The effect of material combination and the diameter was studied. Focusing on the role of surface texturing, metal-on-metal $(\mathrm{MoM})$ and metal-on-PE (MoP) contacts were analysed while three dimple arrays (square, triangle, and circular) were designed. Surprisingly, in the case of MoP contact, the effect of the dimples was found to be negative independently of an array. For MoM, triangular and square arrays led to decreased friction while circular arrangement caused friction increase [22] A phenomenon of elevated friction in some cases was attributed mainly to the larger diameter and the depth of the dimples made by laser texturing. Size of the dimples probably led to starved lubrication conditions eventually. Therefore, an issue of texture geometry was emphasized among others.

Several authors also aimed on the effect of texturing on lubrication performance. Initial numerical study was presented in Ref. [24]. MoM model of the hip implant was developed. Simple cylindrical dimples were modelled considering steady state and walking conditions. The results indicated that texturing of the contact surfaces may have positive effect on the reduction of asperity contact ratio, thus improving the lubrication conditions. The study was later extended, focusing on the lubrication of a knee implant [25]. In such case, the contact of metal femoral and PE tibial components was considered. Combined effect of texturing was observed. Although it was shown that a lateral condyle benefits from the introduced dimples, opposite behaviour was observed for a medial compartment. In Ref. [26], lubrication model of the hip implant was developed aiming on the development of an optimal design of microtextures. It was found that the textures increase load-carrying capacity and the film thickness, together with lowering the contact pressure. The results were supported by experimental investigation of friction with the designed structure pattern. Metal cylinder with the dimpled contact surface rotated against stationary PE specimen while friction decreased by nearly $50 \%$.

It is well known in biotribology that numerical models often suffer from specific limitations such as 
adsorption or agglomeration of proteins which can be hardly simulated. Therefore, an experimental investigation takes place in order to provide relevant information about the lubrication mechanisms. A unique study, combining the direct film thickness measurement together with assessment of the effect of surface texturing, was presented by Choudhury et al. [27]. Contact of metal dimpled ball and glass acetabular cup was observed while the effect of triangular, ellipse, and square dimples on the film thickness development was assessed. Non-dimpled head was considered as a reference while the film thickness was always higher for the textured heads, independently of the dimple shape. In particular, especially in the case of square and triangular dimples, substantial increase of lubricant film was observed.

Based on the above references, it is apparent that surface texturing affects friction, lubrication, and wear which influence the service-life of the joint implants. Various studies were performed, aiming on the various aspects of texturing while positive effect on the tribological performance was observed in the most cases. Nevertheless, it should be emphasized that the authors always considered hard (metal, ceramic) surface to be dimpled. This may lead to negative effect in a long-term point of view. Once the dimples are filled by wear particles, abrasive wear may increase. Therefore, a motivation for the present study is to examine the effect of the dimples made on UHMWPE cup surface in order to lower running-in friction coefficient thus preventing excessive wear. It is suggested that decreased friction at the beginning of operation leads to longer running-in phase, thus ensuring more favourable contact conditions. Eventually, durability of the implants may be extended due to slower wear progression.

\section{Materials and methods}

The experiments were realized using a pendulum hip joint simulator presented in the previous studies $[8,23,28]$. The acetabular cup is fixed by a resin in a stainless steel pot which is mounted to a base frame. The head is attached to a swinging arm using a cone. At the beginning of the experiment, the pendulum arm is deflected to initial position and is released. Spontaneous swinging is then damped due to friction between the ball and the cup. Instantaneous deflection of the pendulum is recorded via an angular velocity sensor. Subsequently, the signal is processed enabling to obtain the friction coefficient. Evaluation is based on a linear model of damping. It should be emphasized that the employed materials exhibit linear decay. Exponential response occurs when viscoelastic materials such as cartilage or hydrogel are introduced. Illustration of the simulator together with the representative decay signal record is shown in Fig. 1.
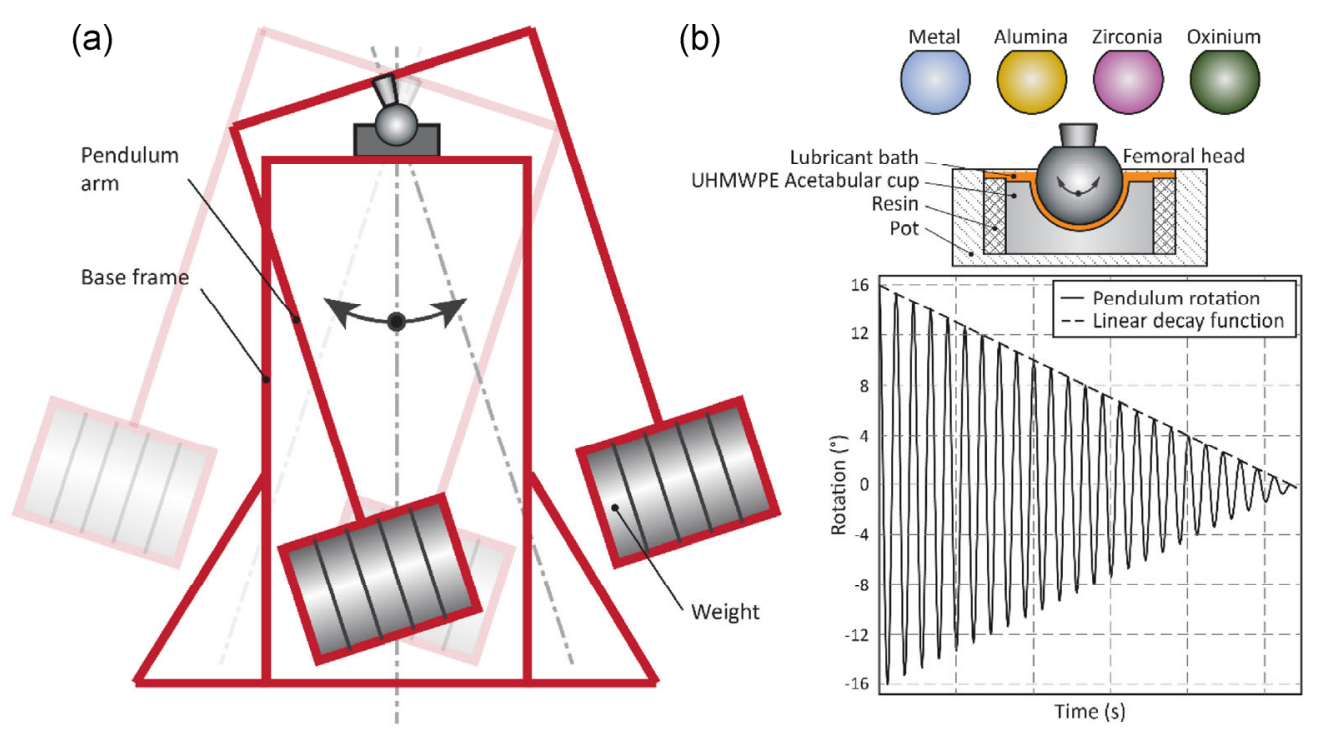

Fig. 1 (a) A schematic illustration of the pendulum hip joint simulator. (b) Overview of the tested femoral components, detail of the contact couple, and representative linear decay signal. 
In the present study, various material combinations were tested. Four commercially available balls were used; metal, alumina ceramic, zirconia toughened ceramic, and oxinium, in particular. Two cups made of UHMWPE (GUR 1050) were tested. The first, reference cup was original without surface texturing. The second cup was fabricated from PE stock with the defined dimensions and the surface roughness corresponding to the original component. Circular dimples were subsequently made on the contact surface. Various approaches may be used for surface texturing. One of the ways is to use a micro drilling. However, the technology suffers from limited accuracy. Another option is to use a laser. Nevertheless, in such case, the diameter and the depth of the dimples cannot be precisely controlled. In addition, the sleeves around the dimples occurring due to elevated temperature leading to increased wear are often observed. Therefore, so-called "tilling" technology, previously successfully applied when texturing aluminium alloy [15], was employed in the present study. The dimples were made by fixing the fabricated UHMWPE cup to a chuck of CNC machining centre. One by one, the dimples were manufactured by removing the material by interrupted micro cutting using an end mill with a cutting edge. It should be emphasized that the process is fully automated and thus very fast. The dimple production rate is about 100 per second. The overall texturing process takes around one minute, dependently on the cup size and dimple pattern design. Therefore, the introduced method is very effective for routine use in large series.

Array and the dimensions of the dimples were designed based on the previous experience of the research team. The diameter and the depth of the dimples were set to 300 and $5 \mu \mathrm{m}$, respectively. The designed coverage ratio was $15 \%$. The shape and the pattern of the dimples could be precisely controlled by adjusting tool path, rotation speed, and feed rate. A macroscopic image of the textured surface, the detail of the group of the dimples, and one random dimple are shown in Fig. 2. Topography map of the bottom of the dented cup is shown in Fig. 3. A nominal diameter of the tested implants was $32 \mathrm{~mm}$. Before the experiments, the surface properties and the actual diameters of all the specimens were carefully checked using a 3D optical profiler and an optical scanning
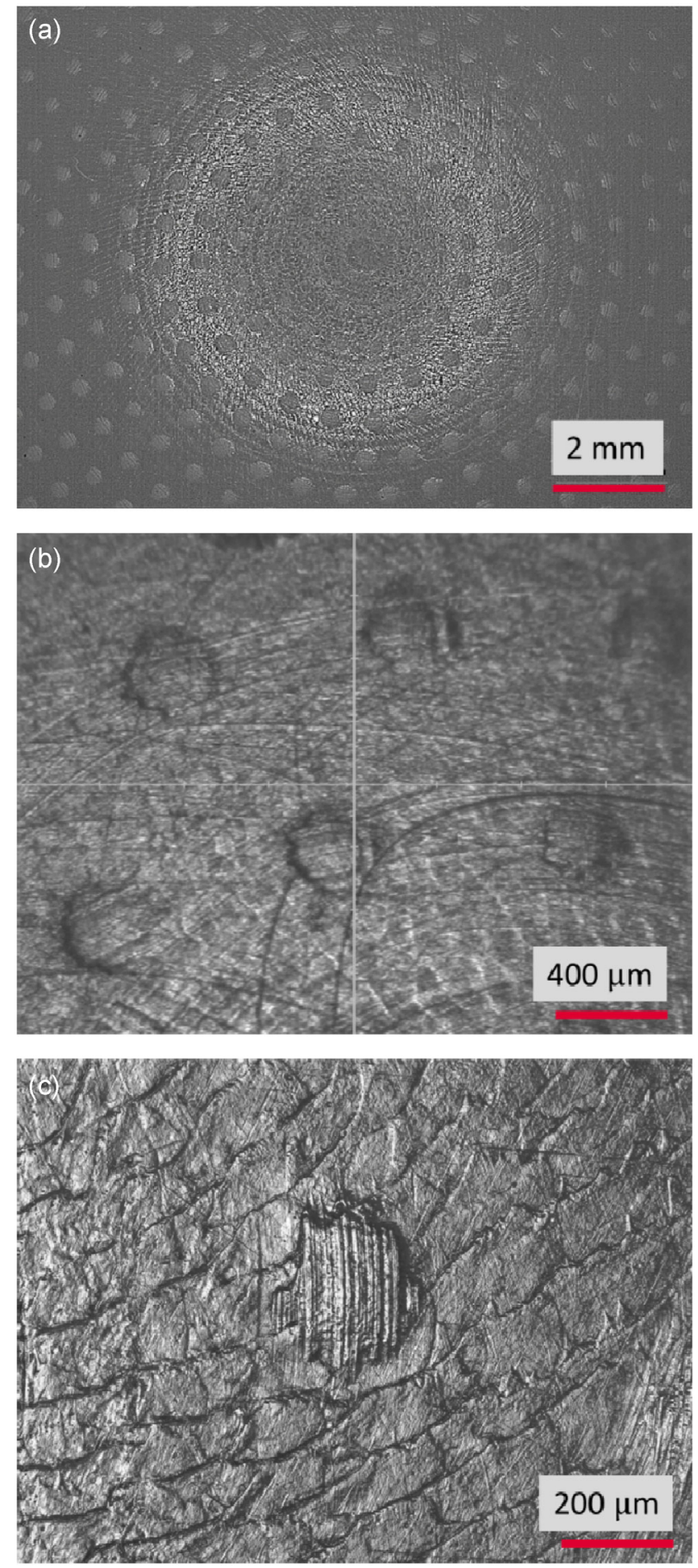

Fig. 2 Macroscopic image of (a) the dimpled cup and (b) group of the dimples taken by laser microscope. (c) Detail of the dimple taken by confocal microscope.

method [29]. Summary of the test samples together with the information about surface roughness, material properties, and contact conditions are presented in Table 1. Although a diametric clearance considering 

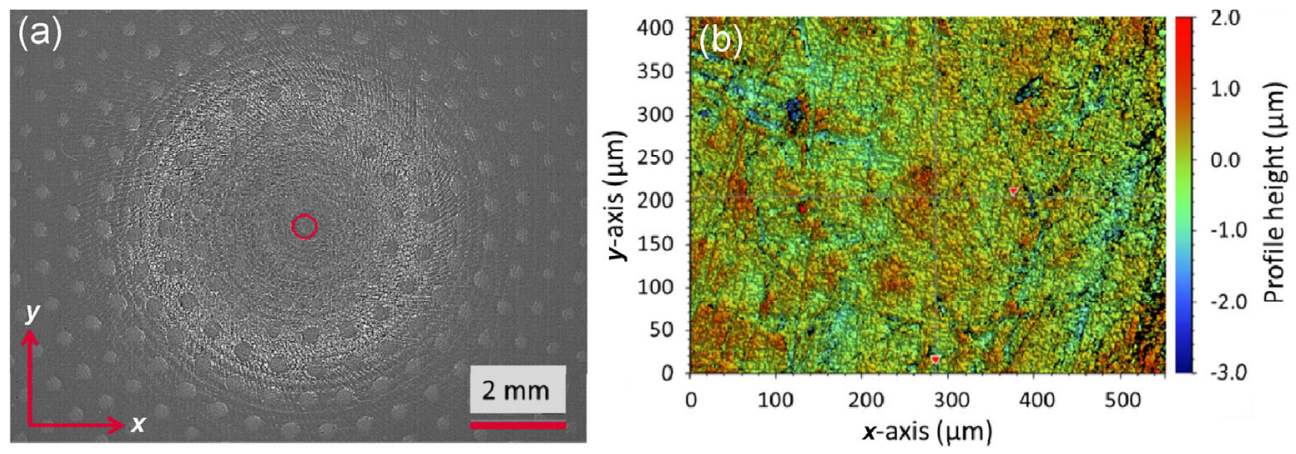

Fig. 3 (a) Macroscopic image of the dimpled cup with the indicated circle area. (b) Topography map within the area.

Table 1 Overview of the test samples and contact conditions.

\begin{tabular}{|c|c|c|c|c|}
\hline Sample & $\begin{array}{l}\text { Actual } \\
\text { diameter } \\
(\mathrm{mm})\end{array}$ & $\begin{array}{l}\text { Surface } \\
\text { roughness } \\
(\mathrm{nm})\end{array}$ & $\begin{array}{c}\text { Elastic } \\
\text { modulus } \\
(\mathrm{GPa})\end{array}$ & $\begin{array}{l}\text { Poisson's } \\
\text { ratio }\end{array}$ \\
\hline Metal head & 31.96 & 12.05 & 230 & 0.29 \\
\hline Alumina head & 31.97 & 9.03 & 340 & 0.28 \\
\hline $\begin{array}{l}\text { Zirconia } \\
\text { toughened } \\
\text { head }\end{array}$ & 31.97 & 12.01 & 320 & 0.28 \\
\hline $\begin{array}{l}\text { Oxinium } \\
\text { head }\end{array}$ & 31.90 & 57.63 & 98 & 0.3 \\
\hline $\begin{array}{l}\text { Original } \\
\text { UHMWPE } \\
\text { cup }\end{array}$ & 32.24 & 573 & 0.8 & 0.37 \\
\hline $\begin{array}{l}\text { Dimpled } \\
\text { UHMWPE } \\
\quad \text { cup }\end{array}$ & 32.35 & 625 & 0.8 & 0.37 \\
\hline \multicolumn{2}{|c|}{ Contact couple } & $\begin{array}{l}\text { Diametric } \\
\text { clearance } \\
(\mu \mathrm{m})\end{array}$ & $\begin{array}{c}\text { Contact } \\
\text { pressure } \\
(\mathrm{MPa})\end{array}$ & $\begin{array}{l}\text { Contact } \\
\text { diameter } \\
(\mathrm{mm})\end{array}$ \\
\hline \multicolumn{2}{|c|}{$\begin{array}{c}\text { Metal-on-original | } \\
\text { metal-on-dimpled }\end{array}$} & $280 \mid 390$ & $3 \mid 3.7$ & $18.5 \mid 16.6$ \\
\hline \multicolumn{2}{|c|}{$\begin{array}{l}\text { Alumina-on-original } \\
\text { alumina-on-dimpled }\end{array}$} & $270 \mid 380$ & $2.9 \mid 3.6$ & $18.7 \mid 16.8$ \\
\hline \multicolumn{2}{|c|}{$\begin{array}{c}\text { Zirconia-on-original } \\
\text { zirconia-on-dimpled }\end{array}$} & $270 \mid 380$ & $2.9 \mid 3.6$ & $18.7 \mid 16.8$ \\
\hline \multicolumn{2}{|c|}{$\begin{array}{l}\text { Oxinium-on-original | } \\
\text { oxinium-on-dimpled }\end{array}$} & $340 \mid 450$ & $3.4 \mid 4$ & $17.4 \mid 15.9$ \\
\hline
\end{tabular}

the dimpled cup is larger, the value is within the tolerances measured for the original commercial UHMWPE cups.

All the experiments were realized under fully flooded conditions. Before the test, the cup was filled by a lubricant. Two various model fluids were employed. Initially, a phosphate buffered saline (PBS) was used as a reference. Subsequently, the contact was lubricated by the designed model SF. It is well known that the proteins significantly influence frictional behaviour of metal/ceramic-on-PE pair [30, 31]. Composition of simulated $\mathrm{SF}$ was as follows: albumin $=20 \mathrm{mg} / \mathrm{ml}, \gamma$-globulin $=3.6 \mathrm{mg} / \mathrm{ml}$, hyaluronic acid $(\mathrm{HA})=2.5 \mathrm{mg} / \mathrm{ml}$, phospholipids $(\mathrm{PH})=0.15 \mathrm{mg} / \mathrm{ml}$; which fits to a physiological SF composition. To avoid results influence due to adsorption of the SF constituents, a strict cleaning procedure was followed. Both the ball and the cup were firstly cleaned by a sodium dodecyl sulphate solution. Subsequently, the components were rinsed by a pure water and dried by a pressed air. Finally, the specimens were washed in an isopropyl alcohol. The attention was also paid to storage conditions. WhilePBS was stored in a fridge, the SF was deeply frozen to $-22{ }^{\circ} \mathrm{C}$ and was stored in a freezer to avoid protein degradation. Prior to the experiments, the lubricants were removed from the freezer/fridge to heat up naturally to an ambient temperature. The experiments were realized under controlled laboratory temperature $\left(22 \pm 1{ }^{\circ} \mathrm{C}\right)$ as it was shown that an elevated temperature to body level does not affect the lubrication conditions [32].

Based on the previous research of lubrication mechanisms within the hip replacements, a load was set to $532 \mathrm{~N}$ for all the tests. Such load level is basically lower compared to physiological conditions. However, it should be emphasized that during the gait cycle, the load is transient with short-term high-load peaks. In the case of the pendulum, the mean load value throughout the cycle corresponds to the mean level of physiological loading. Therefore, it is assumed that the overall load effect is comparable. Resulting contact stresses and the diameters of the contact zones for various couples are stated in Table 1. 
Initial deflection of the pendulum was $16^{\circ}$ and was controlled by a digital angle gauge. In order to provide statistically relevant data, the swinging test was carried out 8 times in a sequence. Once the motion stopped, the pendulum was deflected and released again. In addition, the complete series of the tests were repeated once more another day. All the series of eight swinging tests were performed without the lubricant change or additional supply. It should be noted that the swinging time was from two to four minutes dependently on the contact couple and the applied lubricant. Therefore, the whole series did not last longer than forty minutes. It is expected that the lubricant does not degrade within that time. When the contact couple was changed, fresh lubricant was applied.

\section{Results}

The results for the metal head are shown in Fig. 4 . The friction coefficient for the contact lubricated by PBS is plotted on Fig. 4(a). As can be seen, independently of the tested cup, friction is very stable over the measurement series. In particular, for the original cup, friction is around 0.16 while for the dimpled cup it decreased to around 0.1. In the case of PBS, no fluctuations were observed and the data showed only a little variance. Figure 4(b) shows the data under lubrication by model SF. It is apparent that friction significantly increased compared to PBS. This indicates clear role of the proteins aggregating and adsorbing on the surfaces, thus causing sudden jumps in the results. Focusing on the effect of surface texturing, the dimples led to a substantial lowering of friction from near 0.4 to 0.3 .

Following experiments were conducted with alumina ceramic femoral head. The results are shown in Fig. 5. As in the previous case, PBS results exhibited stable behaviour (Fig. 5(a)). Compared to the metal, friction is much lower. Moreover, the dimples contributed to a further decrease from 0.1 to 0.08 . As is shown in Fig. 5(b), introduction of SF led to relatively scattered results when the original acetabular cup was used. An average value of friction was around 0.29 . The dimples on the cup caused that the behaviour was stabilized and the friction coefficient remarkably dropped to approximately 0.17 .
In the present study, two generations of the ceramic materials were investigated. In the next series of the tests, zirconia toughened ceramic head was employed while the results of friction are plotted in Fig. 6 . Contrary to previous experiments, especially during the first round of testing, PBS led to slightly fluctuating results. Average friction for PBS was around 0.16. Notwithstanding, the positive effect of the dimples could be observed, causing a drop to less than 0.1. Moreover, as is apparent from the graph, friction tendency was stabilized. In the case of SF, continuously increasing friction with each following swinging test was observed for the non-textured cup. The dimples contributed to maintain significantly lower and steady friction (Fig. 6(b)) which was reduced from around 0.36 to 0.22 .

Oxinium is recognized as an advanced material for the joint prostheses combining an advantage of tough elastic core and wear resistive contact surface. The results of the friction coefficient are displayed in Fig. 7. Against expectations, oxinium head exhibited the highest friction from all the tested materials, independently of the applied lubricant. Possible causes of higher friction are discussed below. Focusing on the general effect of surface texturing, the behaviour is similar to previous observations. Friction dropped from 0.34 to 0.25 for PBS and from 0.42 to 0.38 for model SF. Assuming that the most important results regarding potential clinical application are those for simulated SF, the effect of the dimples is not as considerable in the case of oxinium. Although friction is quite high, it was reduced by less than $10 \%$ (Fig. 7(b)).

Figures 4-7 showed development of the friction coefficient for various femoral heads and lubricants. To provide a clear comparison of results, Fig. 8 and Table 2 containing evaluation summary are presented. As is clear from Fig. 8, the dimples on the cup surface led to friction reduction for all the head materials whether the contact was lubricated by PBS or SF. Focusing on the specific results for PBS solution, the dimples helped to decrease friction by $36.3 \%$ (maximumzirconia toughened ceramic) to $19.7 \%$ (minimumalumina ceramic). Summarizing the data for simulated $\mathrm{SF}$, maximum reduction of friction was around $40 \%$ in the case of zirconia toughened ceramic. Considering the alumina ceramic and the metal, friction dropped by $38.8 \%$ and $25.5 \%$, respectively. 

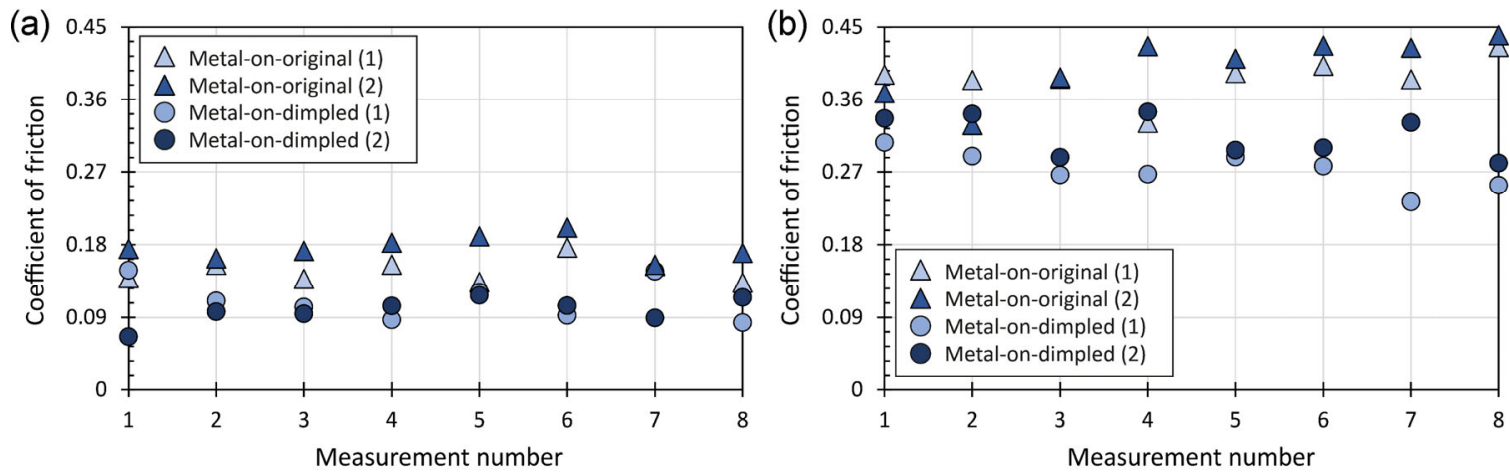

Fig. 4 Results of friction coefficient for metal femoral head using (a) PBS and (b) model SF.
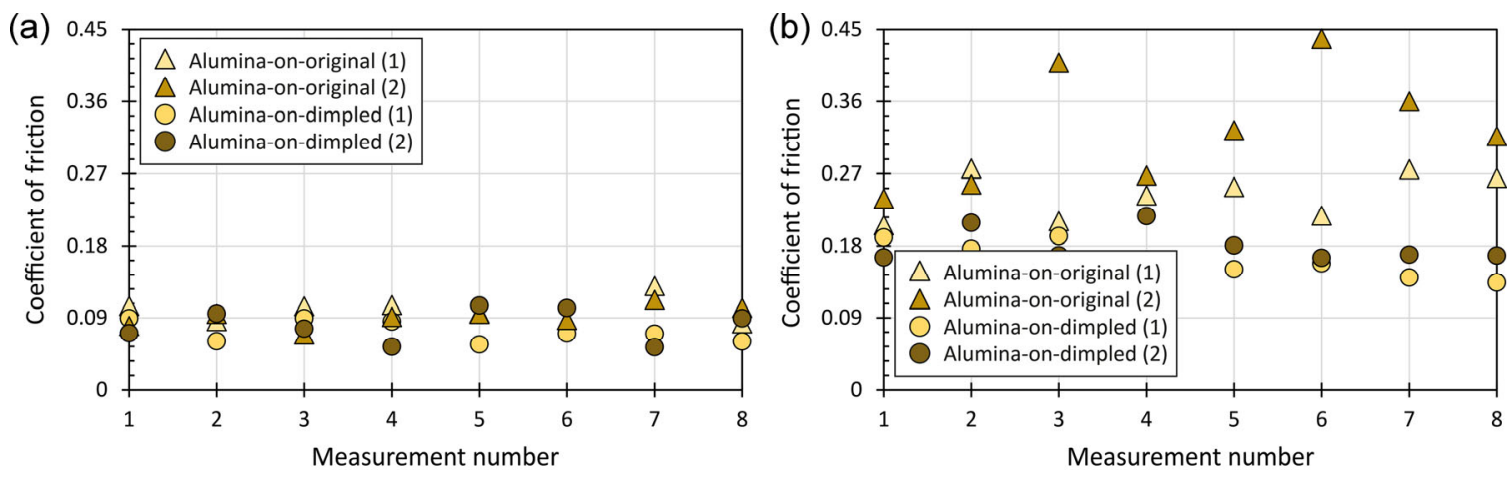

Fig. 5 Results of friction coefficient for alumina ceramic femoral head using (a) PBS and (b) model SF.
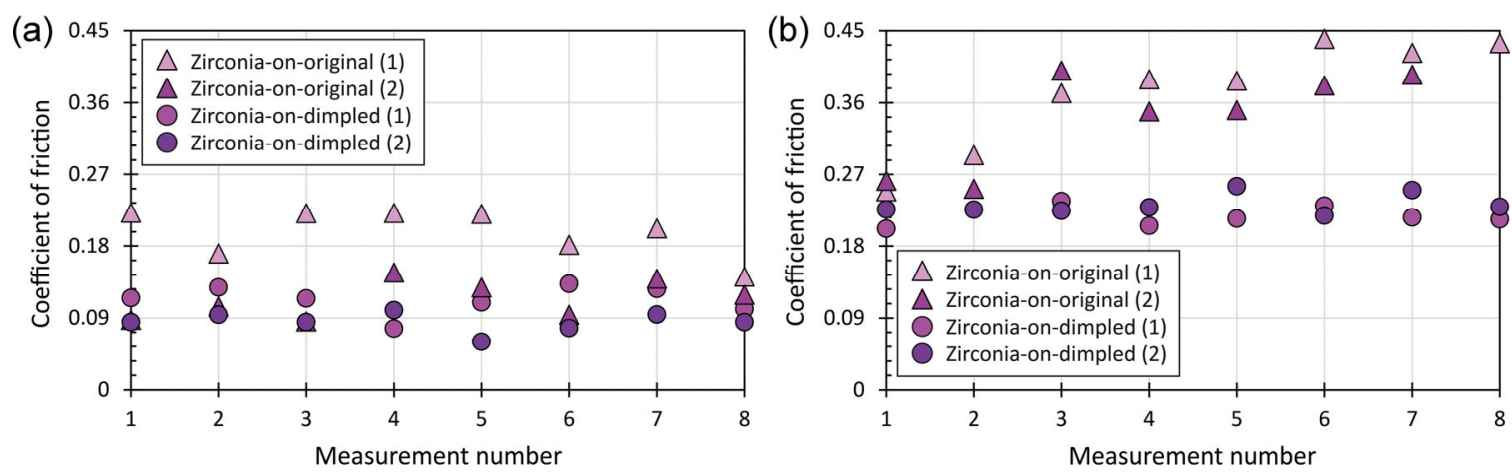

Fig. 6 Results of friction coefficient for zirconia toughened ceramic femoral head using (a) PBS and (b) model SF.
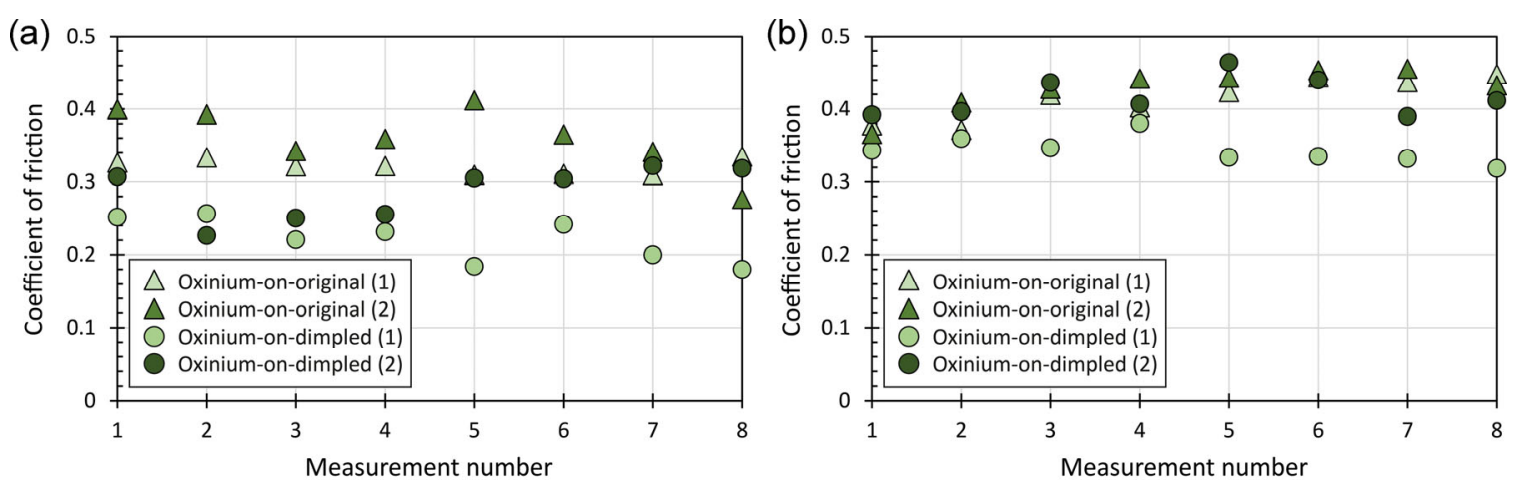

Fig. 7 Results of friction coefficient for oxinium femoral head using (a) PBS and (b) model SF. 


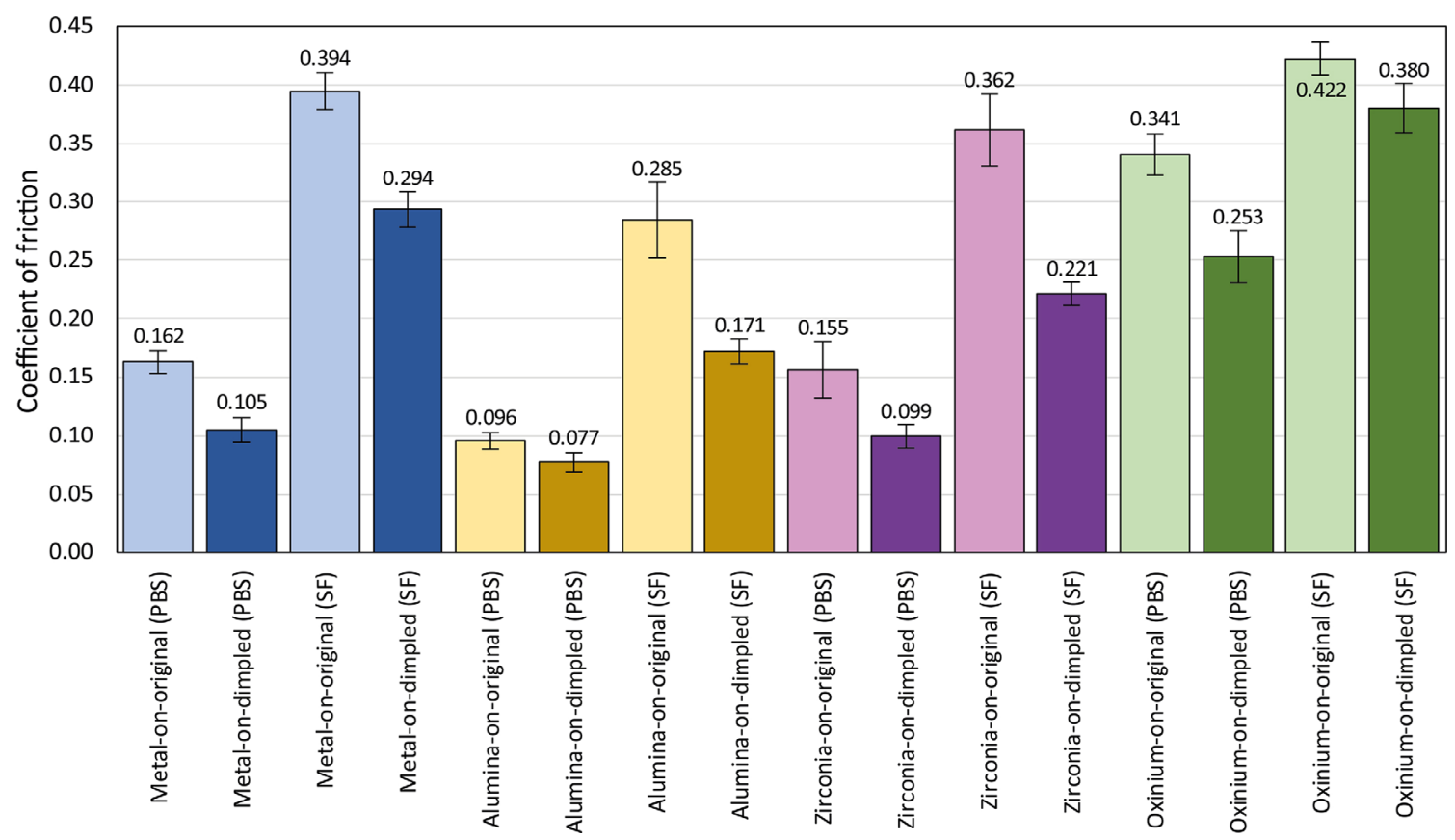

Fig. 8 Results summary (the number above each bar indicates mean coefficient of friction).

Table 2 Results summary: $\mathrm{n}=$ number of measurements; $\mathrm{CoF}=$ coefficient of friction; $\mathrm{SD}=$ standard deviation; $\%$ Diff. $=$ percentage difference, i.e., decrease of friction for the dimpled cup (for mean value).

\begin{tabular}{|c|c|c|c|c|c|c|c|c|}
\hline \multirow[t]{3}{*}{ Cup } & \multicolumn{8}{|c|}{ Metal femoral head } \\
\hline & \multicolumn{4}{|c|}{ PBS solution $(\mathrm{n}=16)$} & \multicolumn{4}{|c|}{ Synovial fluid $(\mathrm{n}=16)$} \\
\hline & Median CoF & Mean CoF & SD & $\%$ Diff. & Median CoF & Mean CoF & SD & $\%$ Diff \\
\hline Original & 0.159 & 0.162 & \pm 0.020 & \multirow{2}{*}{$-35.2 \%$} & 0.392 & 0.394 & \pm 0.031 & \multirow{2}{*}{$-25.5 \%$} \\
\hline \multirow[t]{4}{*}{ Dimpled } & 0.104 & 0.105 & \pm 0.021 & & 0.289 & 0.294 & \pm 0.031 & \\
\hline & \multicolumn{8}{|c|}{ Alumina ceramic femoral head } \\
\hline & \multicolumn{4}{|c|}{ PBS solution $(n=16)$} & \multicolumn{4}{|c|}{ Synovial fluid $(\mathrm{n}=16)$} \\
\hline & Median CoF & Mean CoF & SD & $\%$ Diff. & Median CoF & Mean CoF & SD & $\%$ Diff \\
\hline Original & 0.095 & 0.096 & \pm 0.014 & \multirow{2}{*}{$-19.7 \%$} & 0.266 & 0.285 & \pm 0.066 & \multirow{2}{*}{$-40.0 \%$} \\
\hline \multirow[t]{4}{*}{ Dimpled } & 0.074 & 0.077 & \pm 0.017 & & 0.168 & 0.171 & \pm 0.022 & \\
\hline & \multicolumn{8}{|c|}{ Zirconia toughened ceramic femoral head } \\
\hline & \multicolumn{4}{|c|}{ PBS solution $(n=16)$} & \multicolumn{4}{|c|}{ Synovial fluid $(\mathrm{n}=16)$} \\
\hline & Median $\mathrm{CoF}$ & Mean $\mathrm{CoF}$ & SD & $\%$ Diff. & Median $\mathrm{CoF}$ & Mean $\mathrm{CoF}$ & SD & $\%$ Diff \\
\hline Original & 0.144 & 0.155 & \pm 0.049 & \multirow{2}{*}{$-36.3 \%$} & 0.385 & 0.362 & \pm 0.062 & \multirow{2}{*}{$-38.8 \%$} \\
\hline \multirow[t]{4}{*}{ Dimpled } & 0.097 & 0.099 & \pm 0.020 & & 0.225 & 0.221 & \pm 0.020 & \\
\hline & \multicolumn{8}{|c|}{ Oxinium femoral head } \\
\hline & \multicolumn{4}{|c|}{ PBS solution $(n=16)$} & \multicolumn{4}{|c|}{ Synovial fluid $(\mathrm{n}=16)$} \\
\hline & Median $\mathrm{CoF}$ & Mean CoF & SD & $\%$ Diff. & Median $\mathrm{CoF}$ & Mean CoF & SD & $\%$ Diff \\
\hline Original & 0.334 & 0.341 & \pm 0.035 & \multirow{2}{*}{$-25.7 \%$} & 0.430 & 0.422 & \pm 0.028 & \multirow{2}{*}{$-9.9 \%$} \\
\hline Dimpled & 0.251 & 0.253 & \pm 0.045 & & 0.385 & 0.380 & \pm 0.043 & \\
\hline
\end{tabular}




\section{Discussion}

Within the last few decades, lifespan of the joint replacements became a subject of many debates throughout engineering and medical disciplines [4, 33-35]. Most of the implants fail due to wear-related causes highlighting the necessity of the improved tribological performance [1, 2, 36]. Some of the studies concentrate on the development of new materials or coatings [37-40]. The limitation is that it takes a long time to bring the new materials to practice. In particular, it is necessary to consider risks associated with biocompatibility [41], long-term and complicated process of clinical testing [39], or unexpected behaviour (e.g. delamination in the case of coated implants) [42, 43]. Assuming an expected rapid increase of the joint replacements by 2030 [44], it is highly topical to find a solution which will be easy and fast to implement (a), will not endanger patients (b), and will bring a clear improvement leading to a longer implant survival (c). It is apparent that the development of material, design, or coating application is a long-term process. In order to fulfil three above requirements in a reasonable time frame, together with adequate expenditures, surface modification of the existing implants seems to be an opportunity.

The present study was aimed on evaluation of the friction coefficient of the hip joint replacements. Four commercial femoral heads and two lubricants were tested while the measurements were realized with the original and the dimpled UHMWPE acetabular cup. The research was carried out using the pendulum hip joint simulator enabling to simulate steady-state flexion-extension conditions. The dimples on the cup were fabricated using tilling manufacturing technology. The swinging tests were repeated eight times in order to get statistically relevant data. In addition, the series of experiments for both PBS and SF were repeated another day. Under most conditions, very satisfactory reproducibility of the data was observed. Small differences between the series are attributed mainly to the fact that the same (original/dented) cup was used while its position in the pendulum frame could be slightly different due to twist of the cup.

In order to show a significance of the obtained data, statistical analysis was performed. In total, 256 experiments were conducted (16 measurements for
4 head materials, 2 cups, and 2 lubricants). The data analysis showed that for most of the head-on-cup combinations, the results exhibit normal (Gauss) distribution. However, in some specific cases (aluminaon-original (SF), zirconia-on-original (PBS), and zirconiaon-original (SF), see Fig. 8) apparent data deviation was observed. This variance may be clearly seen in Figs. 5(b) and 6 for the original cup. Therefore, the relevance of these three data sets may be limited. Even though, introduction of the dimpled cup led to friction stabilization which is accompanied by a rapid decrease of a standard deviation (Table 2). Moreover, it should be emphasized that Fig. 8 displays the results of both the measurement series being analysed together. When focusing on individual sets of eight swinging tests, the repeatability and thus the statistical evidence were even better.

Focusing on the effect of the implant material, the lowest friction was observed for ceramic, followed by metal and oxinium. This is in a compliance with previous observations [22, 23, 45]. Regarding two generations of ceramic, lower friction was detected for alumina which also corresponds to literature [4]. Bit surprising is elevated friction in the case of oxinium. Oxinium head is basically metal substrate with contact surface transformed by oxygen diffusion (zirconium $2.5 \%$ niobium alloy) from metallic to a low-friction ceramic nature [46]. Worse frictional behaviour reported in this paper is attributed to a significantly higher surface roughness resulting to the contact of surface asperities, thus leading to a transition from mixed to boundary lubrication regime [47]. In addition, diameter of the oxinium head is smaller compared to metal or ceramic. Therefore, it is suggested that the larger diametric clearance also contributes to higher friction due to insufficient lubrication conditions [10].

The difference in size of the diametric clearance considering the original and the dimpled cup needs to be clarified as well. As stated in Table 1, the difference in clearance is $110 \mu \mathrm{m}$ while the dimpled cup exhibits generally larger clearance. In order to confirm the effect of the dimples, it is referred to previously published study using the same simulator and following the same experimental procedure [23]. In that case, the implants of nominal diameters of 28 and $36 \mathrm{~mm}$ supplied by two various producers were investigated. It should be noted that the difference in clearance 
for both metal-on-PE and ceramic-on-PE pairs was always higher than that in the present study. Nevertheless, despite a significant clearance difference, variance in friction was very limited for most of the tested couples. In addition, larger clearance usually led to higher friction. Thus, it is assumed that the lower friction observed for the dimpled cups (having larger clearance) in the present paper may be attributed mainly to the dimple effect.

Behaviour of the joint replacements is indisputably influenced by the properties of the lubricant. Human synovial joints are lubricated by SF. Ability of film formation and viscosity of SF are driven especially by content and ratio of the included constituents [48, 49]. An issue of optimal model fluid for laboratory tests, suitably mimicking human body conditions, is often discussed. The authors commonly employ bovine serum (BS) solution with given overall protein content [50]. However, the content of specific constituents is rarely declared in the case of BS. Moreover, the composition may vary producer to producer as well as series to series. Therefore, it is suggested that despite the number of studies employing BS, it might be not an optimal equivalent lubricant mimicking the behaviour of human SF [51, 52]. Following this implication, the model SF was designed while the detailed composition is stated above. The concentration of the constituents is based on evaluation of the samples of human SF extracted from the patients during surgeries [53]. The designed fluid composition corresponds to a physiological level. Other sets of the tests were performed with PBS to get a reference. Independently of the head material, PBS exhibited lower friction compared to simulated SF. This confirms previous findings that the proteins cause a rapid increase of friction considering the metal/ceramic-onPE contact pair [30, 54-56].

Focusing on the particular values of friction, the data seem to be higher than usually reported. However, it must be emphasized that the most of the studies describing very low friction factors often deal with a simplified configuration (e.g., pin-on-disc) considering low loads at low speeds. Therefore, comparable results come from the experiments performed using the hip simulator employing real ball-on-cup model [22, 23, 45]. In all the mentioned studies, $25 \%$ BS was used as the test lubricant. When comparing the results for metal and ceramic heads, friction observed in Refs. [22, 23] was nearly double compared to that presented in Ref. [45].

Generally higher friction coefficient is attributed mainly to the increased concentration of SF constituents which is indisputably higher than in the case of $25 \%$ BS. In addition, it is assumed that higher concentration of albumin $(20 \mathrm{mg} / \mathrm{ml})$ is responsible for elevated friction as previously shown [54]. The level of applied load may contribute as well. As is stated in materials and methods section, the applied load was designed in order to mimic average physiological load effect throughout the walking cycle. However, the lower load causes the phenomenon of slippage at the moment of pendulum reversal. According to our previous experience, when higher load is applied, slippage during reversal is mitigated, thus leading to lower friction. Finally, it should be emphasized that the arrangement of the ball and the cup is in inversed position to enable the contact to be fully flooded which may also play a role. Therefore, it is assumed that higher friction is due to a combination of higher protein concentration (a), substantially higher content of albumin (b), lower level of load (c), and inversed geometrical arrangement (d). However, when investigating the behaviour of the joint replacements, it should be emphasized that the specific value of friction/wear rate/film thickness is not as decisive. The importance comes from the general comparison of the effect of various inputs on the observed parameter. Therefore, the main outcome of the introduced paper is the percentage difference in friction considering the original and the dimpled cup.

Regarding the potential implication for practice, the important findings are related to model SF behaviour (Table 2, Figs. 4(b), 5(b), 6(b), and 7(b)). Independently of the head material, friction was significantly reduced by introducing the dimples. The highest reduction rate was observed for alumina ceramic (40\%) followed by zirconia toughened ceramic (38.8\%), metal $(25.5 \%)$, and oxinium $(9.9 \%)$. As can be seen, the lower initial friction, the larger friction reduction for simulated SF. Moreover, it is assumed that reduction of wear would be even higher than reduction of friction. As was shown by Roy et al. [21], who studied pin-on-disc contact of ceramic counterfaces, surface texturing led to $22 \%$ friction reduction, resulting in 
$53 \%$ wear rate reduction. Thus, it is expected that even in the case of oxinium, exhibiting relatively insignificant friction reduction, wear rate might be lowered substantially.

Another benefit of the dimples can be observed especially in the case of the ceramic heads. Introduction of the dimples led to evident stabilization of the friction coefficient, indicating more favourable contact conditions (Figs. 5(b) and 6(b)). When thinking about the mechanism of friction reduction, it is suggested that there are two essential factors. Enhanced lubricant film formation due to storage of the fluid within the cavities is considered to be the first factor [16]. The second point is the reduced contact asperity ratio eventually contributing to improved lubrication conditions [24]. The second statement is supported by the results of oxinium head having higher surface roughness, thus resulting to limited dimple effect.

Positive role of the dimples was already pronounced in both experimental [16-22] and numerical [24-26] studies. However, the previous papers considered hard (metal/ceramic) surfaces to be textured. An explanation for such motivation seems to be logical. At first, it is much easier to make the texture on the hard convex shape. Moreover, it is suggested that the dimples on a soft matter material (such as PE) might be removed after some time due to articulation of surfaces. Nevertheless, this might be a key. As mentioned in introduction part, wear is progressive especially during running-in phase. Subsequently, the process is stabilized with slowly and continuously increasing wear rate $[5,6]$. Although there is a substantial contribution of PE creep during running-in $[6,57,58]$, friction doubtlessly plays a role as well. Therefore, it is concluded that the dimples made on UHMWPE cup are able to diminish running-in friction and wear. After some time, the surface of the cup is polished due to articulation having positive effect on surface roughness. This leads to a reduction of the contact asperity ratio, enabling the implant to operate smoothly for longer time.

The amount of wear particles released during running-in period can be hardly estimated. Nevertheless, it is expected that wear rate might be lowered significantly, since it was shown that wear reduction well correlates to friction reduction [59]. The authors feel a strong motivation for further investigation. The present results are fundamental. Nevertheless, there is a lot of aspects which need to be clarified in future research. The main attention should be paid to finding the optimal parameters of the dimples in terms of the geometry and the surface coverage ratio in order to maximize friction reduction.

The authors admit the limitations of the pendulum simulator. However, it should be emphasized that the pendulum has been representing well-established tool for friction investigation of the joint replacements for decades. It has been used not only by the scientists, it can be found in laboratories of producers of the implants as well. Assuming the importance of surface conformity, number of studies using multi-directional test stations when measuring friction is very limited so far [60-62]. Moreover, the pendulum is sometimes used in order to validate the multi-axial measurements [63]. Therefore, the authors are convinced that despite the simplified loading and kinematic conditions, the pendulum provides valuable data regarding further development of the implants. Positive role of the dimples should be confirmed also in terms of wear using multi-directional hip simulators with transient kinematic and loading conditions to better mimic in vivo situation. Simultaneous monitoring of wear and friction represents a challenging task for further studies. The effect of the combination of the textured cup and the textured head should be clarified as well.

A further shortcoming of the present paper is the use of limited number of the cups. It should be noted that only one dimpled cup was available for this study. After the manufacturing, the shape and the dimensions were carefully checked while the dimples were fabricated subsequently. Regarding the original cup, detailed shape, surface, and dimension analysis of three commercial implants was conducted with the use of 3D optical scanning [29] and optical profiler. Based on the analysis, the cup exhibiting minimum sphericity deviation together with the required roughness and the actual diameter was used. In order to prevent results influence due to wear of the cups, a sequence of the experiments with the given fluids was kept the same (firstly PBS, then SF). Also an order of the heads was the same (metal, alumina, zirconia, and oxinium). Nevertheless, it should be noted that despite the number of the experiments, there was almost no wear. The imaging using laser 
microscope showed that the number of scratches was very limited. Therefore, it is assumed that the results should not be affected by the fact that only two cups (one original and one dimpled) were used.

Focusing on the limitations of the present paper, the performed study was purely experimental. In order to confirm the observed phenomena, numerical solution would be helpful. The research team has been involved in the development of numerical model for the determination of lubricant film thickness within the hip implant. It is suggested that in future, this model should be further developed in order to enable estimation of the coefficient of friction. Then, the effect of the textured geometry could be easily verified by means of numerical simulation.

\section{Conclusions}

According to author's best knowledge, the present study introduces the first experimental investigation of frictional behaviour of the hip joint replacements using the surface-textured UHMWPE acetabular cup. The main findings can be summarized in the following points.

1) The tilling technology enables to manufacture very precise dimples on the shaped soft-matter surfaces without undesirable sleeves occurring due to thermal influence of the surface in the case of laser texturing.

2) Under lubrication by model SF, the dimples on the cup surface led to a significant reduction of friction independently of the head material. In addition, the textured cup exhibited stabilized frictional behaviour without sudden fluctuations.

3) The texturing of PE acetabular cups represents an easy, time and cost undemanding, and apparently effective way to lower running-in friction of the joint replacements. Moreover, since conventional, wellestablished materials may be used, there is no threat for the patients associated with clinical testing of new materials or coating layers.

4) It is deeply believed that lower friction during running-in phase substantially reduces running-in wear. This may slow down the overall wear process which eventually leads to extended service life of the implants. If this assumption would be confirmed by long-term wear test and clinical study, introduction of surface texturing would improve the life quality of millions of patients and would safe an amount of financial costs associated with the revising operations.

\section{Acknowledgements}

The research was carried out under the project JSPS/OF280, PE17046 with financial support from the Japan Society for the Promotion of Science. This research was also supported by the project FSI-S-17-4415 with financial support from the Ministry of Education, Youth and Sports of the Czech Republic (MEYS). The study was also supported by the project LTAUSA17150 with financial support from MEYS. The authors would like to thank Kanefusa Corporation for dimple manufacturing and M. Černohlávek for his help with the experiments.

Open Access This article is licensed under a Creative Commons Attribution 4.0 International Li-cense, which permits use, sharing, adaptation, distribution and reproduction in any medium or for-mat, as long as you give appropriate credit to the original author(s) and the source, provide a link to the Creative Commons licence, and indicate if changes were made.

The images or other third party material in this article are included in the article's Creative Commons licence, unless indicated otherwise in a credit line to the material. If material is not in-cluded in the article's Creative Commons licence and your intended use is not permitted by statutory regulation or exceeds the permitted use, you will need to obtain permission directly from the copyright holder.

To view a copy of this licence, visit http://creativecommons.org/licenses/by/4.0/.

\section{References}

[1] Gallo J, Goodman S B, Konttinen Y T, Wimmer M A, Holinka M. Osteolysis around total knee arthroplasty: A review of pathogenetic mechanisms. Acta Biomater 9(9): 8046-8058 (2013)

[2] Gallo J, Vaculova J, Goodman S B, Konttinen Y T, Thyssen J P. Contributions of human tissue analysis to understanding the mechanisms of loosening and osteolysis in total hip replacement. Acta Biomater 10(6): 2354-2366 (2014) 
[3] Tandon P N, Jaggi S. Wear and lubrication in an artificial knee joint replacement. Int J Mech Sci 23(7): 413-422 (1981)

[4] Rieker C B. Tribology of total hip arthroplasty prostheses: What an orthopaedic surgeon should know. EFORT Open Rev 1(2): 52-57 (2016)

[5] Penmetsa J R, Laz P J, Petrella A J, Rullkoetter P J. Influence of polyethylene creep behavior on wear in total hip arthroplasty. J Orthop Res 24(3): 422-427 (2006)

[6] Zeman J, Ranuša M, Vrbka M, Gallo J, Křupka I, Hartl M. UHMWPE acetabular cup creep deformation during the run-in phase of THA's life cycle. J Mech Behav Biomed Mater 87: 30-39 (2018)

[7] Myant C, Cann P. On the matter of synovial fluid lubrication: Implications for Metal-on-Metal hip tribology. J Mech Behav Biomed Mater 34: 338-348 (2014)

[8] Vrbka M, Nečas D, Hartl M, Křupka I, Urban F, Gallo J. Visualization of lubricating films between artificial head and cup with respect to real geometry. Biotribology 1-2: 61-65 (2015)

[9] Myant C W, Cann P. The effect of transient conditions on synovial fluid protein aggregation lubrication. $J$ Mech Behav Biomed Mater 34: 349-357 (2014)

[10] Nečas D, Vrbka M, Urban F, Gallo J, Křupka I, Hartl M. In situ observation of lubricant film formation in THR considering real conformity: The effect of diameter, clearance and material. J Mech Behav Biomed Mater 69: 66-74 (2017)

[11] Nečas D, Vrbka M, Galandáková A, Křupka I, Hartl M. On the observation of lubrication mechanisms within hip joint replacements. Part I: Hard-on-soft bearing pairs. J Mech Behav Biomed Mater 89: 237-248 (2019)

[12] Nečas D, Vrbka M, Rebenda D, Gallo J, Galandáková A, Wolfová L, Křupka I, Hartl M. In situ observation of lubricant film formation in THR considering real conformity: The effect of model synovial fluid composition. Tribol Int 117: 206-216 (2018)

[13] Ali F, Krrupka I, Hartl M. Reducing the friction of lubricated nonconformal point contacts by transverse shallow microgrooves. Proc Inst Mech Eng Part J J Eng Tribol 229(4): 420-428 (2015)

[14] Gachot C, Rosenkranz A, Hsu S M, Costa H L. A critical assessment of surface texturing for friction and wear improvement. Wear 372-373: 21-41 (2017)

[15] Usami H, Sato T, Kanda Y, Nishio S. Applicability of Interrupted Micro Cutting Process "Tilling” as Surface Texturing. Key Eng Mater 749: 241-245 (2017)

[16] Ito H, Kaneda K, Yuhta T, Nishimura I, Yasuda K, Matsuno T. Reduction of polyethylene wear by concave dimples on the frictional surface in artificial hip joints. $J$ Arthroplasty 15(3):
332-338 (2000)

[17] Sawano H, Warisawa S, Ishihara S. Study on long life of artificial joints by investigating optimal sliding surface geometry for improvement in wear resistance. Precis Eng 33(4): 492-498 (2009)

[18] Borjali A, Langhorn J, Monson K, Raeymaekers B. Using a patterned microtexture to reduce polyethylene wear in metal-onpolyethylene prosthetic bearing couples. Wear 392-393: 7783 (2017)

[19] Langhorn J, Borjali A, Hippensteel E, Nelson W, Raeymaekers B. Microtextured CoCrMo alloy for use in metal-onpolyethylene prosthetic joint bearings: Multi-directional wear and corrosion measurements. Tribol Int 124: 178-183 (2018)

[20] Cho M, Choi H J. Optimization of surface texturing for contact between steel and ultrahigh molecular weight polyethylene under boundary lubrication. Tribol Lett 56(3): 409-422 (2014)

[21] Roy T, Choudhury D, Ghosh S, Mamat A B, PingguanMurphy B. Improved friction and wear performance of micro dimpled ceramic-on-ceramic interface for hip joint arthroplasty. Ceram Int 41(1): 681-690 (2015)

[22] Choudhury D, Vrbka M, Mamat A B, Stavness I, Roy C K, Mootanah R, Krupka I. The impact of surface and geometry on coefficient of friction of artificial hip joints. $J$ Mech Behav Biomed Mater 72: 192-199 (2017)

[23] Vrbka M, Nečas D, Bartošík J, Hartl M, Křupka I, Galandáková A, allo J. Determination of a Friction Coefficient for THA Bearing Couples. Acta Chir Orthop Traumatol Čech 82(5): 341-347 (2015)

[24] Gao L M, Yang P R, Dymond I, Fisher J, Jin Z M. Effect of surface texturing on the elastohydrodynamic lubrication analysis of metal-on-metal hip implants. Tribol Int 43(10): 1851-1860 (2010)

[25] Gao L M, Hua Z K, Hewson R, Andersen M S, Jin Z M. Elastohydrodynamic lubrication and wear modelling of the knee joint replacements with surface topography. Biosurf Biotribol 4(1): 18-23 (2018)

[26] Chyr A, Qiu M F, Speltz J W, Jacobsen R L, Sanders A P, Raeymaekers B. A patterned microtexture to reduce friction and increase longevity of prosthetic hip joints. Wear 315(1-2): 51-57 (2014)

[27] Choudhury D, Rebenda D, Sasaki S, Hekrle P, Vrbka M, Zou M. Enhanced lubricant film formation through microdimpled hard-on-hard artificial hip joint: An in-situ observation of dimple shape effects. $J$ Mech Behav Biomed Mater 81: 120-129 (2018)

[28] Stanton T E. Boundary lubrication in engineering practice. Engineer 29: 678-680 (1923)

[29] Ranuša M, Gallo J, Vrbka M, Hobza M, Paloušek D, 
Křupka I, Hartl M. Wear analysis of extracted polyethylene acetabular cups using a 3D optical scanner. Tribol Trans 60(3): 437-447 (2017)

[30] Nečas D, Sawae Y, Fujisawa T, Nakashima K, Morita T, Yamaguchi T, Vrbka M, Křupka I, Hartl M. The Influence of proteins and speed on friction and adsorption of metal/ UHMWPE contact pair. Biotribology 11: 51-59 (2017)

[31] Sawae Y, Murakami T, Chen J. Effect of synovia constituents on friction and wear of ultra-high molecular weight polyethylene sliding against prosthetic joint materials. Wear 216(2): 213-219 (1998)

[32] Mavraki A, Cann P M. Lubricating film thickness measurements with bovine serum. Tribol Int 44(5): 550-556 (2011)

[33] Evans J T, Walker R W, Evans J P, Blom A W, Sayers A, Whitehouse M R. How long does a knee replacement last? A systematic review and meta-analysis of case series and national registry reports with more than 15 years of followup. Lancet 393(10172): 655-663 (2019)

[34] di Puccio F, Mattei L. Biotribology of artificial hip joints. World J Orthop 6(1): 77-94 (2015)

[35] Isaac G H. Life cycle aspects of total replacement hip joints. Tribol Interface Eng Ser 48: 147-160 (2005)

[36] Rao A J, Gibon E, Ma T, Yao Z Y, Smith R L, Goodman S B. Revision joint replacement, wear particles, and macrophage polarization. Acta Biomater 8(7): 2815-2823 (2012)

[37] Lappalainen R, Santavirta S S. Potential of coatings in total hip replacement. Clin Orthop Relat Res 430: 72-79 (2005)

[38] Choudhury D, Lackner J M, Major L, Morita T, Sawae Y, Mamat A B, Stavness I, Roy C K, Krupka I. Improved wear resistance of functional diamond like carbon coated Ti-6Al$4 \mathrm{~V}$ alloys in an edge loading conditions. $J$ Mech Behav Biomed Mater 59: 586-595 (2016)

[39] Haider H, Weisenburger J N, Namavar F, Garvin K L. Why coating technologies for hip replacement systems, and the importance of testing them in vitro. Oper Tech Orthop 27(3): 152-160 (2017)

[40] Balla V K, Banerjee S, Bose S, Bandyopadhyay A. Direct laser processing of a tantalum coating on titanium for bone replacement structures. Acta Biomater 6(6): 2329-2334 (2010)

[41] Goodman S B, Gómez Barrena E, Takagi M, Konttinen Y T. Biocompatibility of total joint replacements: A review. $J$ Biomed Mater Res A 90A(2): 603-618 (2009)

[42] Rahaman M N, Huang T, Bal B S, Li Y. In vitro testing of $\mathrm{Al}_{2} \mathrm{O}_{3}-\mathrm{Nb}$ composite for femoral head applications in total hip arthroplasty. Acta Biomater 6(2): 708-714 (2010)

[43] Łapaj Ł, Markuszewski J, Wendland J, Mróz A, WieruszKozłowska M. Massive failure of TiNbN coating in surface engineered metal-on-metal hip arthroplasty: Retrieval analysis.
J Biomed Mater Res B Appl Biomater 104(5): 1043-1049 (2016)

[44] Kurtz S, Ong K, Lau E, Mowat F, Halpern M. Projections of primary and revision hip and knee arthroplasty in the United States from 2005 to 2030. J Bone Joint Surg Am 89(4): 780-785 (2007)

[45] Brockett C, Williams S, Jin Z M, Isaac G, Fisher J. Friction of total hip replacements with different bearings and loading conditions. J Biomed Mater Res B Appl Biomater 81B(2): 508-515 (2007)

[46] Ozden V E, Saglam N, Dikmen G, Tozun I R. Oxidized zirconium on ceramic; Catastrophic coupling. Orthop Traumatol Surg Res 103(1): 137-140 (2017)

[47] Sagbas B. Biotribology of artificial hip joints. In Advances in Tribology. Darji P H, Ed. Croatia: InTechOpen, 2016.

[48] Park J B, Duong C T, Chang H G, Sharma A R, Thompson M S, Park S, Kwak B C, Kim T Y, Lee S S, Park S. Role of hyaluronic acid and phospholipid in the lubrication of a cobaltchromium head for total hip arthroplasty. Biointerphases 9(3): 031007 (2014)

[49] Smith A M, Fleming L, Wudebwe U, Bowen J, Grover L M. Development of a synovial fluid analogue with bio-relevant rheology for wear testing of orthopaedic implants. $J$ Mech Behav Biomed Mater 32: 177-184 (2014)

[50] Essner A, Schmidig G, Wang A G. The clinical relevance of hip joint simulator testing: In vitro and in vivo comparisons. Wear 259(7-12): 882-886 (2005)

[51] Parkes M, Myant C, Cann P M, Wong J S S. Synovial fluid lubrication: The effect of protein interactions on adsorbed and lubricating films. Biotribology 1-2: 51-60 (2015)

[52] Mazzucco D, McKinley G, Scott R D, Spector M. Rheology of joint fluid in total knee arthroplasty patients. J Orthop Res 20(6): 1157-1163 (2002)

[53] Galandáková A, Ulrichová J, Langová K, Hanáková A, Vrbka M, Hartl M, Gallo J. Characteristics of synovial fluid required for optimization of lubrication fluid for biotribological experiments. J Biomed Mater Res B Appl Biomater 105(6): 1422-1431 (2017)

[54] Crockett R, Roba M, Naka M, Gasser B, Delfosse D, Frauchiger V, Spencer N D. Friction, lubrication, and polymer transfer between UHMWPE and CoCrMo hip-implant materials: A fluorescence microscopy study. J Biomed Mater Res A 89A(4): 1011-1018 (2009)

[55] Gispert M P, Serro A P, Colaço R, Saramago B. Friction and wear mechanisms in hip prosthesis: Comparison of joint materials behaviour in several lubricants. Wear 260(1-2): 149-158 (2006)

[56] Guezmil M, Bensalah W, Mezlini S. Tribological behavior of UHMWPE against $\mathrm{TiAl}_{6} \mathrm{~V}_{4}$ and $\mathrm{CoCr}_{28}$ Mo alloys under 
dry and lubricated conditions. J Mech Behav Biomed Mater 63: 375-385 (2016)

[57] Engh C A Jr, Stepniewski A S, Ginn S D, Beykirch S E, Sychterz-Terefenko C J, Hopper R H Jr, Engh C A. A randomized prospective evaluation of outcomes after total hip arthroplasty using cross-linked marathon and non-crosslinked enduron polyethylene liners. J Arthroplasty 21(6): 17-25 (2006)

[58] Higuchi Y, Seki T, Morita D, Komatsu D, Takegami Y, Ishiguro N. Comparison of wear rate between ceramic-onceramic, metal on highly cross-linked polyethylene, and metalon-metal bearings. Rev Bras Ortop 54(3): 295-302 (2019)

[59] Wang A, Essner A, Klein R. Effect of contact stress on friction and wear of ultra-high molecular weight polyethylene in total hip replacement. Proc Inst Mech Eng H J Eng Med 215(2): 133-139 (2001)

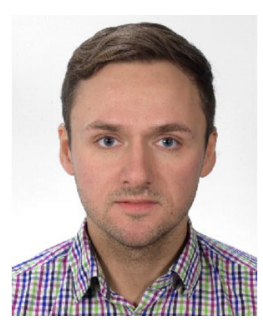

David NEČAS. He received his B.S., M.S., and Ph.D. degrees in mechanical engineering from Brno University of Technology, Czech Republic, in 2010, 2012, and 2016, respectively. His current position is an assistant professor and member of

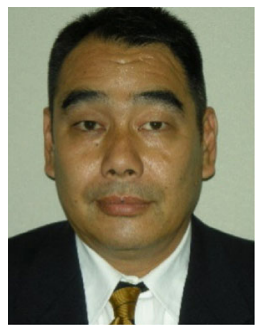

Hatsuhiko USAMI. He received his B.S. degree from Meijo University, and M.S. and Ph.D. degrees in mechanical engineering from Nagoya Institute of Technology, Japan. From 1995, he has been working for

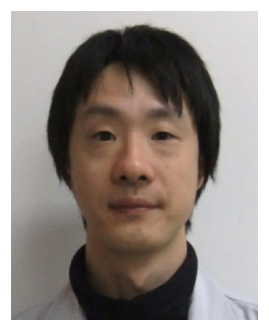

Tatsuya NIIMI. He received his B.S. degree in electrical and electronic engineering from Gifu University, Japan, in 2010. His current
[60] Damm P, Dymke J, Ackermann R, Bender A, Graichen F, Halder A, Beier A, Bergmann G. Friction in total hip joint prosthesis measured in vivo during walking. PLoS One 8(11): e78373 (2013)

[61] Kaddick C, Malczan M, Buechele C, Hintner M, Wimmer M A. On the measurement of three-dimensional taper moments due to friction and contact load in total hip replacement. In Modularity and Tapers in Total Joint Replacement Devices. Greenwald A, Kurtz S, Lemons J, Mihalko W, Eds. West Conshohocken, PA: ASTM International, 2015.

[62] Haider H, Weisenburger J N, Garvin K L. Simultaneous measurement of friction and wear in hip simulators. Proc Inst Mech Eng H J Eng Med 230(5): 373-388 (2016)

[63] Sonntag R, Braun S, Al-Salehi L, Reinders J, Mueller U, Kretzer J P. Three-dimensional friction measurement during hip simulation. PLoS One 12(9): e0184043 (2017)

Biotribology Research Group at Institute of Machine and Industrial Design, Faculty of Mechanical Engineering, Brno University of Technology. His research areas cover friction and lubrication of joint replacements, tribological performance of articular cartilage, and soft EHL lubrication.

Mechanical Engineering Department of Meijo University. His current position is a professor and a member of Materials Science and Engineering Department. His research areas focus on material design including surface modification and texturing for tribological application.

position is an engineer of Kanefusa Corporation. His research areas cover effects of surface texture fabricated by interrupted micro cutting on tribological properties. 


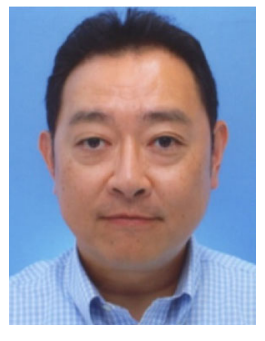

Yoshinori SAWAE. He received his B.S., M.S., and Dr. Eng. degrees in mechanical engineering from Kyushu University, Japan, in 1991, 1993, and 1997, respectively. He joined Department of Mechanical Engineering, Faculty of Engineering,

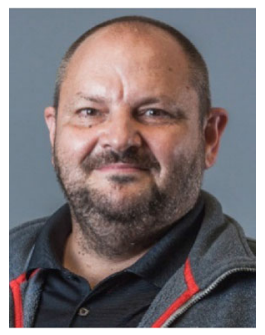

Ivan Ǩ̌UPKA. He received his M.S. and Ph.D. degrees in mechanical engineering from Brno University of Technology, Czech Republic, in 1990 and 1997, respectively. His current position is a professor and

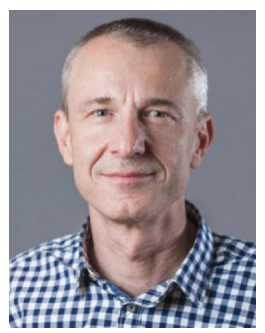

Martin HARTL. He received his M.S. and Ph.D. degrees in mechanical engineering from Brno University of Technology, Czech Republic, in 1990 and 1997, respectively. His current position is a professor and
Kyushu University as a lecturer in 1996 and became a professor of Machine Elements and Design Engineering Laboratory in 2011. His primal research area is biotribology, especially working on the in vivo wear mechanism of prosthetic joint materials and the lubrication mechanism of natural synovial joint.

head of Tribology Group, Institute of Machine and Industrial Design, Faculty of Mechanical Engineering, Brno University of Technology. His research areas cover the mixed and elastohydrodynamic lubrication, surface texturing effect, and lubricant rheology.

head of Institute of Machine and Industrial Design, Faculty of Mechanical Engineering, Brno University of Technology. His research areas cover the boundary, mixed and elastohydrodynamic lubrication, roughness effect, and biotribology. 